\title{
STUDI PENGARUH MAGNETISASI BAHAN BAKAR BIODIESEL TERHADAP KEKUATAN DIELEKTRIK
}

\author{
Ariek Sulistyowati, Emir Ridwan, Tatun H Nufus ${ }^{1}$, Budi Yuwono, Budi Santoso \\ Jurusan Teknik Mesin, Politeknik Negeri Jakarta, Jl. GA Siwabessy Kampus UI Depok, 16425. \\ e-mail : ${ }^{1}$ thnufus@gmail.com
}

\begin{abstract}
One of the efforts to determine the quality of combustion on the egine is the dielectric constant, therefore the purpose of this study is to make a device to test the fuel dielectric constants and observe the effect of the magnetic field strength on the fuel dielectric constant, the dielectric constant measurement is done by measuring the capacitance through a capacitor plate made of copper PCB and LCR measuring instrument. Initial testing uses air as the object at the same time for calibration. Furthermore, the object used is a mixture of biodiesel and diesel fuel. these data are compared between the biodiesel dielectric constant without the influence of magnetism and with biodiesel fuel which is influenced by magnetic fields. The measurement results show thatThe dielectric constant value of the frequency range $0 \mathrm{~Hz}$ to $550 \mathrm{~Hz}$ has fluctuations up and down so that the value is random. The frequency range of $600 \mathrm{~Hz}$ to $2000 \mathrm{~Hz}$ dielectric constant tends to decrease exponentially as frequency increases. The greater the magnetic field given to the biodiesel fuel, the smaller the dielectric constant value. this means that the moment of the dipole is more directed so that the combustion process can take place better.
\end{abstract}

Key words : magnet field, biodiesel, dielectric constanta.

\begin{abstract}
ABSTRAK
Salah satu upaya untuk mengetahui kualitas pembakaran pada engine yaitu konstanta dielektrik, oleh karena itu tujuan penelitian ini adalah membuat alat untuk menguji konstata dielektrik bahan bakar dan mengamati pengaruh kuat medan magnet terhadap konstanta dielektrik bahan bakar tersebut, pengukuran konstanta dielektrik dilakukan dengan cara mengukur kapasitansinya yaitu melalui plat kapasitor terbuat dari PCB tembaga dan alat ukur LCR. Pengujian awal menggunakan udara sebagai objeknya sekaligus untuk kalibrasi. Selanjutnya objek yang digunakan bahan bakar campuran biodiesel dan solar. Data-data ini dibandingkan antara konstanta dielektrik biodiesel tanpa pengaruh magnet dan dengan bahan bakar biodiesel yang dipengaruhi medan magnet. Hasil pengukuran menunjukkan bahwa nilai konstanta dielektrik rentang frekuensi $0 \mathrm{~Hz}$ sampai $550 \mathrm{~Hz}$ mengalami fluktuasi naik turun sehingga nilainya acak. Rentang frekuensi $600 \mathrm{~Hz}$ sampai $2000 \mathrm{~Hz}$ nilai konstanta dielektrik cenderung menurun secra eksponensial seiring dengan bertambahnya frekuensi.Semakin besar medan magnet yang diberikan pada bahan bakar biodiesel semakin kecil nilai konstanta dielektriknya.artinya momen dipolenya semakin terarah sehingga proses pembakaran dapat berlangsung lebih baik.
\end{abstract}

Kata kunsi :medan magnet, biodiesel, konstanta dielektrik.

\section{PENDAHULUAN}

Banyak peneliti menyatakan bahwa bahan bakar yang dimagnetisasi mengalami perubahan molekul dari yang bergumpal (cluster) menjadi tidak bergumpal (decluster), efek dari perubahan ini proses pembakaran menjadi lebih sempurna sehingga konsumsi bahan bakar pada engine menjadi lebih irit dan emisi gas buangnya lebih bersih. Sebagian besar peneliti membuktikannya melalui pengujian FTIR dan UV visible [1][2]. Pada penelitian ini kualitas pembakaran pada engine dibuktikan melalui pengukuran konstanta dielektrik. Hal ini dilakukan mengingat konstanta dielektrik merupakan salah satu parameter yang dapat menunjukkan tingkat kemampuan pengutuban molekul non polar (bahan bakar) [[2][2][2]. Hipotesanya makin tinggi konstanta dielektriknya makin besar molekul-molekul bahan bakar yang 
terpolarisasi atau molekulnya makin banyak yang berubah dari cluster menjadi de cluster. Sehingga reaksi antara bahan bakar dan udara lebih homogen dan pembakaran yang terjadi menjadi lebih sempurna [1].

\section{METODE PENELITIAN}

Metoda penelitian dilakukan secara eksprimental, data diperoleh dengan cara pengamatan, pengukuran langsung dilapangan dengan alat ukur yang tersedia.

Penelitian dilakukan di Politeknik Negeri Jakarta, Laboratorium Fisika dan Konversi Energi, Jurusan Teknik Mesin.

Peralatan yang digunakan pada penelitian adalah PCB tembaga, penggaris, pemotong $\mathrm{PCB}$, jangka sorong, kabel tunggal, solder dan perekat, konektor L dan H, LCR Meter GW Instek seri 816, dan pipet tetes. Bahan yang digunakan adalah bahan bakar biodiesel yang dimagnetisasi.

Tahapan awal penelitian yaitu pembuatan plat kapasitor sebagai alat untuk meletakkan sampel yang akan dilakukan pengukuran. Plat kapasitor terbuat dari PCB tembaga dengan ukuran $20 \mathrm{~mm}$ x $10 \mathrm{~mm}$ dan memiliki jarak $5 \mathrm{~mm}$, selanjutnya plat tersebut dirangkai dengan LCR meter seperti terlihat pada Gambar 1.

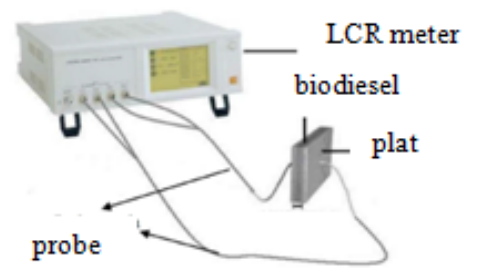

Gambar 1. Rangkaian pengukuran

Tahap selanjutnya pengujian alat untuk mengetahui keakuratan dan presisi dari sistem pengukuran. Pengujian sistem dilakukan dengan cara melakukan pengukuran nilai konstanta dielektrik udara pada plat kapasitor. Nilai yang dihasilkan dari hasil pengukuran harus sesuai dengan nilai konstanta dielektrik udara pada literatur. Pengukuran kapasitansi udara dilakukan pada frekuensi rendah. yaitu $100 \mathrm{~Hz}-2000$ $\mathrm{Hz}$ dengan interval $100 \mathrm{~Hz}$. Pengukuran kapasitansi udara dilakukan sebanyak 5 kali. Data hasil pengukuran dirata-ratakan mengguna kan persamaan (1) [2]

$$
\bar{C}=\frac{\Sigma C}{n}
$$

Selanjutnya nilai kapasitansi udara ini dimasukkan pada persamaan (2) untuk memperoleh konstanta dielektrik udara. Bila nilai konstanta dielektriknya sama dengan literatur maka alat ini layak digunakan.

$$
\varepsilon^{\prime}=\frac{C \cdot d}{\varepsilon_{0} \cdot A}
$$

Keterangan:

$\mathrm{C}=$ Kapasitansi

$\mathrm{n}=$ Jumlah pengukuran

$\mathrm{d}=$ Jarak antar plat

$\mathrm{A}=$ Luas Plat

$\varepsilon^{\prime}=$ Konstanta dielektrik sampel

$\varepsilon_{0}=$ konstanta dielektrik udara

\section{HASIL dan PEMBAHASAN}

Gambar 3 memperlihatkan grafik hubungan antara konstanta dielektrik dengan frekuensi tampak bahwa semakin besar frekuensi yang diberikan, nilai konstanta dielektrik mengalami penurunan, hal ini disebabkan nilai konstanta dielektrik berbanding terbalik dengan nilai frekuensi.

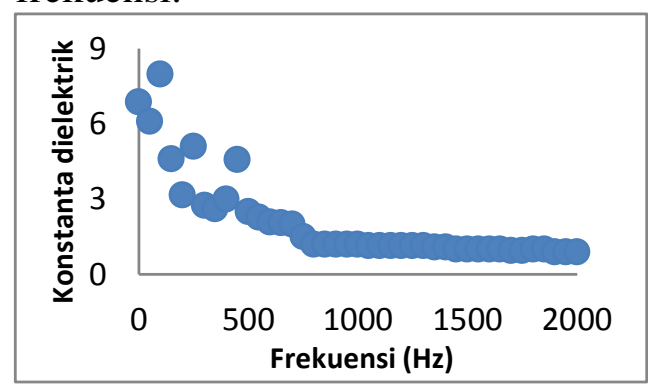

Gambar 3. Frekuensi dengan Konstanta Dielektrik udara 
Berdasarkan Gambar 3 tampak bahwa semakin besar frekuensi yang diberikan, nilai konstanta dielektrik terjadi mengalami penurunan,hal ini disebabkan nilai konstanta dielektrik berbanding terbalik dengan nilai frekuensi. Menurut Halliday nilai konstanta dielektrik udara pada ruang hampa yaitu 1 [2]. dan konstanta dielektrik untuk udara hasil penelitian yaitu 1,00327 dengan demikian kesalahan relatifnya sebesar $0,27 \%$. Mengingat kesalahannya sangat kecil maka alat ini dapat digunakan untuk pengukuran nilai konstanta dielektrik bahan yang lain.

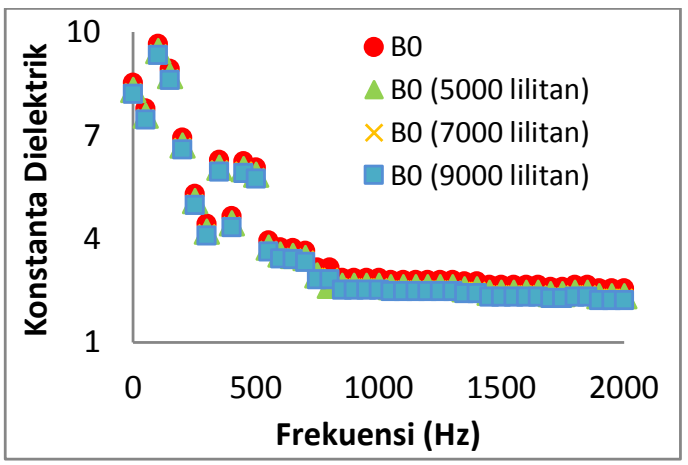

Gambar 4 Frekuensi dengan

Konstanta Dielektrik bahan bakar solar (B0)

Gambar 4 memperlihatkan konstanta dielektrik untuk bahan bakar solar (B0) baik yang dimagnetisasi maupun tidak. Tampak bahwa B0 yang dimagnetisasi dengan jumlah lilitan 5000 memiliki konstanta dielektrik rata-rata pada frekuensi $(0-2000 \mathrm{~Hz})$ adalah 3.66 sedang konstanta dielektrik pada frekuensi $500-200 \mathrm{~Hz}$ besarnya adalah 2.63. Sedang bila jumlah lilitannya ditingkatkan hingga 7000 maka konstanta dielektrik menurun pada frekuensi $(0-2000 \mathrm{~Hz})$ yaitu 3.56 dan frekuensi $500-200 \mathrm{~Hz}$ besarnya adalah 2.49, B0 diberi medan magnet electromagnet dengan jumlah lilitan 9000 memiliki konstanta dielektrik rata-rata pada frekuensi $(0-2000 \mathrm{~Hz})$ adalah 3.46 sedang konstanta dielektrik pada frekuensi $500-200 \mathrm{~Hz}$ besarnya adalah 2.41. konstanta dielektrik ini berubah menjadi lebih kecil dibandingkan dengan bahan bakar yang tidak diberi medan magnet, makin besar medan magnet atau jumlah lilitan makin banyak makin kecil konstanta dielektrik bahan bakar, hal ini diesebabkan karena bahan bakar tesebut memperoleh tambahan energy dai magnet, energi ini dipergunakan untuk merubah posisinya dari yang tidak teratur menjadi lebih teratur atau terarah

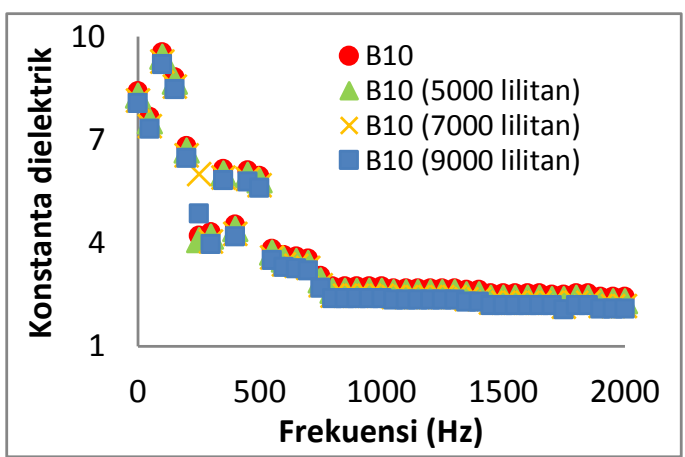

Gambar 5. Frekuensi dengan

Konstanta Dielektrik bahan bakar solar+biodiesel (B10)

Gambar 5 menyajikan konstanta dielektrik untuk bahan bakar campuran $90 \%$ solar dan $10 \%$ biodiesel (B10) baik yang dimagnetisasi maupun tidak. Tampak bahwa B10 yang dimagnetisasi dengan jumlah lilitan 5000 memiliki konstanta dielektrik rata-rata pada frekuensi $(0-2000 \mathrm{~Hz})$ adalah 3.72 sedang konstanta dielektrik pada frekuensi 500-200 Hz besarnya adalah 2.67. Sedang bila jumlah lilitannya ditingkatkan hingga 7000 maka konstanta dielektrik menurun pada frekuensi $(0-2000 \mathrm{~Hz})$ yaitu 3.68 dan frekuensi $500-200 \mathrm{~Hz}$ besarnya adalah 2.63. B10 diberi medan magnet electromagnet dengan jumlah lilitan 9000 memiliki konstanta dielektrik rata-rata pada frekuensi $(0-2000 \mathrm{~Hz})$ adalah 3.61 sedang konstanta dielektrik pada frekuensi $500-200 \mathrm{~Hz}$ besarnya adalah 2.56 .

Konstanta dielektrik ini berubah menjadi lebih kecil dibandingkan 
dengan bahan bakar yang tidak diberi medan magnet, makin besar medan magnet maka makin kecil konstanta dielektrik bahan bakar, hal ini disebabkan karena bahan bakar tesebut memperoleh tambahan energi dari magnet, energi ini dipergunakan untuk merubah posisinya dari yang tidak teratur menjadi lebih teratur atau terarah.

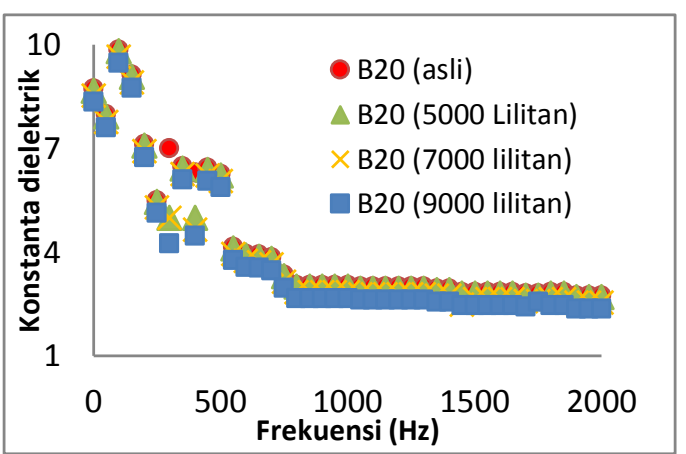

Gambar 6. Frekuensi dengan

Konstanta Dielektrik bahan bakar solar+biodiesel (B20)

Gambar 6 menyajikan konstanta dielektrik untuk bahan bakar campuran 90\% solar dan 10\% biodiesel (B20) baik yang dimagnetisasi maupun tidak. Tampak bahwa B20 yang dimagnetisasi dengan jumlah lilitan 5000 memiliki konstanta dielektrik rata-rata pada frekuensi $(0-2000 \mathrm{~Hz})$ adalah 4.09 sedang konstanta dielektrik pada frekuensi $500-200 \mathrm{~Hz}$ besarnya adalah 3.03. Sedang bila jumlah lilitannya ditingkatkan hingga 7000 maka konstanta dielektrik menurun pada frekuensi $(0-2000 \mathrm{~Hz})$ yaitu 3.93 dan frekuensi $500-200 \mathrm{~Hz}$ besarnya adalah 2.86. B20 diberi medan magnet electromagnet dengan jumlah lilitan 9000 memiliki konstanta dielektrik rata-rata pada frekuensi $(0-2000 \mathrm{~Hz})$ adalah 3.75 sedang konstanta dielektrik pada frekuensi $500-200 \mathrm{~Hz}$ besarnya adalah 2.71 .

Konstanta dielektrik ini berubah menjadi lebih kecil dibandingkan dengan bahan bakar yang tidak diberi medan magnet, makin besar medan magnet maka makin kecil konstanta dielektrik bahan bakar, hal ini disebabkan karena bahan bakar tesebut memperoleh tambahan energi dari magnet, energi ini dipergunakan untuk merubah posisinya dari yang tidak teratur menjadi teratur.

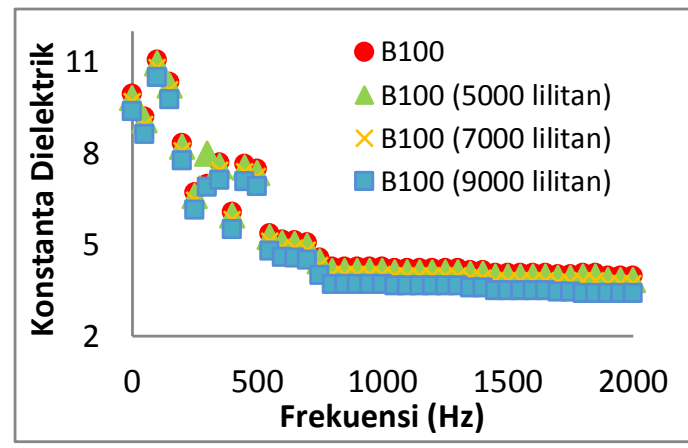

Gambar 7. Frekuensi dengan

Konstanta Dielektrik bahan bakar solar+biodiesel (B100)

Gambar 7 menyajikan konstanta dielektrik untuk bahan 100\% biodiesel (B100) baik yang dimagnetisasi maupun tidak. Tampak bahwa B100 yang dimagnetisasi dengan jumlah lilitan 5000 memiliki konstanta dielektrik rata-rata pada frekuensi (0$2000 \mathrm{~Hz}$ ) adalah 5.14 sedang konstanta dielektrik pada frekuensi $500-200 \mathrm{~Hz}$ besarnya adalah 4.05. Sedang bila jumlah lilitannya ditingkatkan hingga 7000 maka konstanta dielektrik menurun pada frekuensi $(0-2000 \mathrm{~Hz})$ yaitu 5.28 dan frekuensi $500-200 \mathrm{~Hz}$ besarnya adalah 4.18. B20 diberi medan magnet electromagnet dengan jumlah lilitan 9000 memiliki konstanta dielektrik rata-rata pada frekuensi (0$2000 \mathrm{~Hz}$ ) adalah 4.82 sedang konstanta dielektrik pada frekuensi $500-200 \mathrm{~Hz}$ besarnya adalah 3.72 .

Konstanta dielektrik ini berubah menjadi lebih kecil dibandingkan dengan bahan bakar yang tidak diberi medan magnet, makin besar medan magnet maka makin kecil konstanta dielektrik bahan bakar, hal ini disebabkan karena bahan bakar tesebut memperoleh tambahan energi dari magnet, energi ini dipergunakan untuk merubah posisinya dari yang tidak teratur menjadi teratur [2]. 


\section{KESIMPULAN}

Hasil pengukuran menunjukkan bahwa metode dielektrik dapat digunakan untuk mengukur karakteristik bahan bakar biodiesel berupa nilai konstanta dielektrik. Nilai konstanta dielektrik rentang frekuensi $0 \mathrm{~Hz}$ sampai $550 \mathrm{~Hz}$ mengalami fluktuasi naik turun sehingga nilainya acak. Rentang frekuensi $600 \mathrm{~Hz}$ sampai $2000 \mathrm{~Hz}$ nilai konstanta dielektrik cenderung menurun secra eksponensial seiring dengan bertambahnya frekuensi. Semakin besar medan magnet yang diberikan pada bahan bakar biodiesel semakin kecil nilai konstanta dielektriknya. Makin besar komposisi biodiesel dalam campuran maka konstanta dielektriknya makin menuju ke konstanta biodiesel murni.

\section{UCAPAN TERIMA KASIH}

Terima kasih pada P3M-PNJ yang telah bersedia memberikan dana penelitian melalui skema penelitian unggulan program studi.

\section{DAFTAR PUSTAKA}

[1] Chalid M., N. Saksono, N. Darsono, D. Teknik, F. Teknik, U. Indonesia, D. T. Kimia, F. Teknik, and U. Indonesia, 2005, "Studi pengaruh magnetisasi sistem dipol terhadap karakteristik kerosin”, Makara Teknol., vol. 8, no. 1, pp. 36-42.

[2] De Souza E., J. M. Peko, D. L. S.Reis, and A. R. L. Caires, 2013, "Evaluation of the dielectric properties of biodiesel fuels produced from different vegetable oil feedstocks through electrochemical impedance spectroscopy," pp. 16-20.

[3] Faris A. S., S. K. Al-Naseri, N. Jamal, R. Isse, M. Abed, Z. Fouad,A. Kazim, N. Reheem, A.
Chaloob, H. Mohammad, H. Jasim, J. Sadeq, A. Salim, and A. Abas, 2012, “Effects of magnetic field on fuel consumption and exhaust emissions in two-stroke engine," Energy Procedia, vol. 18, pp. 327-338.

[4] Govindasamy P. and S. Dhandapani, 2009, "Effects of Egr \& Magnetic Fuel Treatment System on Engine Emission Characteristics in a Bio Fuel Engine," in

[5] Guo H., Z. Liu, Y. Chen, and R. Yao, 2011, A study of magnetic effects on the physicochemical properties of individual hydrocarbon, vol. 3. pp. 216-220. International Conference on Mechanical Engineering, vol. 1, no. December, pp. 26-28.

[6] Halliday and Resnic, 1992, Physics, 3rd ed. USA: Willey and sons.

[7] Juansah J., 2007, "Kajian sifat dielektrik buah semangka dengan pemanfaatan sinyal listrik frekuensi rendah, "J Sains MIPA, vol. 13, no. 3, pp. 159-164.

[8] Yu C. Y., L. Y. Huang, I. C. Kuan, and S. L. Lee, 2013, "Optimized production of biodiesel from waste cooking oil by lipase immobilized on magnetic nanoparticles," Int. J. Mol. Sci., vol. 14, no. 12, pp. 24074-24086. 
Ariek Sulistyowati dkk, Studi Pengaruh Magnetisasi .... 